\title{
Linaclotide Acetate
}

National Cancer Institute

\section{Source}

National Cancer Institute. Linaclotide Acetate. NCI Thesaurus. Code C77223.

The acetate salt form of linaclotide, a synthetic, fourteen amino acid peptide and agonist of intestinal guanylate cyclase type C (GC-C), which is structurally related to the guanylin peptide family, with secretag ogue, analgesic and laxative activities. Upon oral administration, linaclotide binds to and activates GC-C receptors located on the luminal surface of the intestinal epithelium. This increases the concentration of intracellular cyclic guanosine monophosphate (cGMP), which is derived from guanosine triphosphate (GTP). cGMP activates the cystic fibrosis transmembrane conductance regulator (CFT R) and stimulates the secretion of chloride and bicarbonate into the intestinal lumen. This promotes sodium excretion into the lumen and results in increased intestinal fluid secretion. This ultimately accelerates GI transit of intestinal contents, improves bowel movement and relieves constipation. Increased extracellular cGMP levels may also exert an antinociceptive effect, through an as of yet not fully elucidated mechanism, that may involve modulation of nociceptors found on colonic afferent pain fibers. Linaclotide is minimally absorbed from the Gl tract. 